\title{
APPLICATION OF GLOBAL OPTIMIZATION TO PREDICT STRAINS IN RC COMPRESSED COLUMNS
}

\author{
MAREK Lechman $^{a, *}$, AndrZeJ Stachurski $^{b}$ \\ ${ }^{a}$ Building Research Institute, Filtrowa 1, 00-611, Warsaw, Poland \\ ${ }^{b}$ Warsaw University of Technology, Institute of Control and Computation Engineering, Nowowiejska 15/19, \\ 00-665 Warsaw, Poland \\ * corresponding author: m.lechman@itb.pl
}

Abstract. In this paper, the results of an application of global and local optimization methods to solve a problem of determination of strains in RC compressed structure members are presented. Solutions of appropriate sets of nonlinear equations in the presence of box constraints have to be found. The use of the least squares method leads to finding global solutions of optimization problems with box constraints. Numerical examples illustrate the effects of the loading value and the loading eccentricity on the strains in concrete and reinforcing steel in the cross-section.

Three different minimization methods were applied to compute them: trust region reflective, genetic algorithm tailored to problems with real double variables and particle swarm method. Numerical results on practical data are presented. In some cases, several solutions were found. Their existence has been detected by the local search with multistart, while the genetic and particle swarm methods failed to recognize their presence.

KEYwORDs: Global optimization, nonlinear equations, least squares method, RC compressed structure members.

\section{INTRODUCTION}

Our problem is to determine the normal strains in the cross-sections of reinforced concrete structure members subjected to compression. Mathematically, it may be formulated as a task of solving sets of equations with box constraints. The unknown variables are: $\epsilon^{\prime}-$ maximum strain in the cross section and $\xi-$ coordinate describing the location of the neutral axis.

The presence of the box constraints makes a direct use of numerical methods for solving sets of nonlinear equations impractical. Therefore, our task is reformulated by means of the frequently used least squares method. It leads to a nonlinear, nonconvex optimization problem of finding a minimum of a nonlinear function with the restricted scope of variables.

\subsection{Motivation to STUdy The STRAins IN RC COMPRESSED STRUCTURE MEMBERS}

Reinforced concrete structure members subjected to the compression are frequently encountered in the engineering practice (columns, pillars, tower-like structures etc.). The determination of strains is very important in the safety assessment of existing RC structures. In order to solve this problem analytically, several physical models of materials and methods were proposed. Lechman and Lewiński [1] considered a generalized linear section model. A simplified approach based on the rectangular stress distribution for concrete was used by Knauff [2] and Knauff et al. 3]. Nieser and Engel [4] and CICIND [5] applied the parabola-rectangle diagram for the design of cross-sections.
For reinforcing steel itself, both linear and nonlinear models are used, see for instance Lechman and Stachurski [6], Lechman [7-10], where the ring sections were investigated. The results of FE (finite element) modelling of failure behaviour of RC compressed columns were presented by Majewski et al. [11] and Rodriguez et al. [12. In Kim and Lee [13, a numerical method for predicting the behaviour of $\mathrm{RC}$ columns subjected to axial force and biaxial bending is proposed and verified in tests. Campione et al. [14] experimentally investigated the behaviour of compressed concrete columns subjected to the overcoring technique, see also Campione et al. [15]. The list of researchers working in various directions could be continued. Let's mention some of them: Lloyd and Rangan [16, Bonet et al. [17, Ye et al. [18, Xu et al. [19], Trapko and Musiał [20, Trapko [21, Hadi and Le [22], El Maddawy et al. [23], Csuka and Kollar [24], Elwan and Rashed [25], Sadeghian et al. [26], Eid and Paultre [27], Wu and Jiang [28, Quiertant and Clement [29], Lee et al. [30, Kumar and Patel [31] and many others. Of course, the list is not complete.

Despite the variety of calculation methods and experimental investigations concerning this problem, there are not any appropriate analytical solutions based on the nonlinear material laws for determining the strains in RC externally compressed structure members that considers concrete softening.

The aim of our paper is twofold. Firstly, to formulate equilibrium equations allowing to calculate the strains. Secondly, to investigate the usefulness of some 

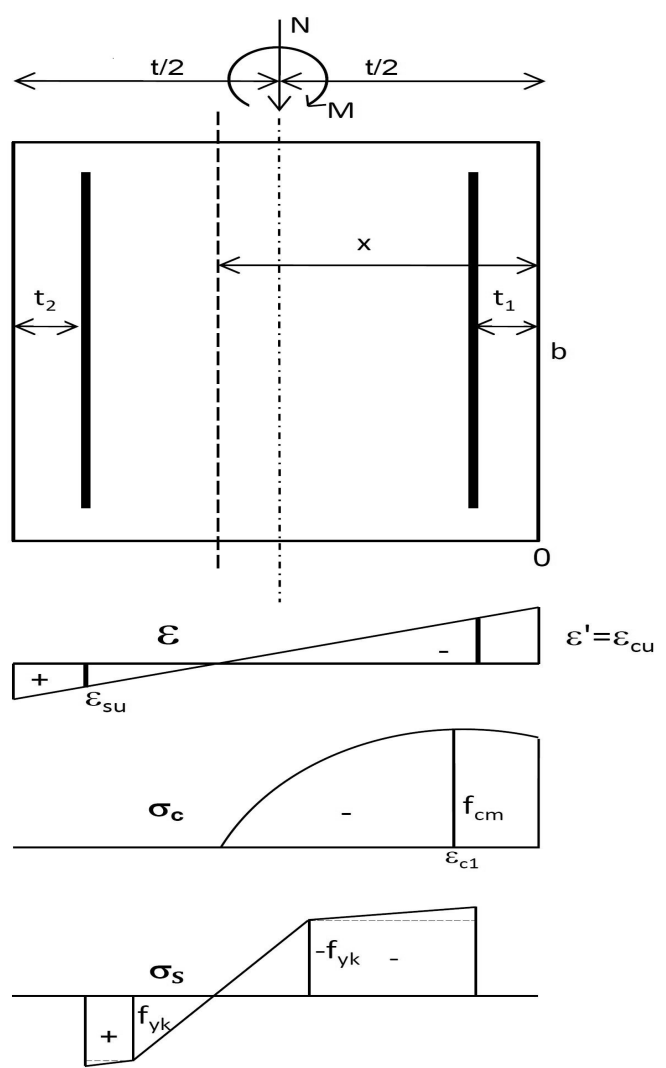

Figure 1. Distribution of strain $\epsilon$, stresses in concrete $\sigma_{c}$ and stresses in steel $\sigma_{s}$ across the section

global optimization methods to solve the problem numerically.

\section{Formulation of the EQUilibrium EQUATIONS}

To get the required equations, we started with the integral equilibrium equations and integrated them. The rectangular RC cross-section is subjected to the axial force $N$ and the bending moment $M$ (see Fig. 1). The content of the current section is an extension of that presented in Lechman and Stachurski 32. The detailed way of deriving the formulas for the section wholly in compression is included.

In the derivation of the governing equations, the following assumptions are made:

- plane cross-sections remain plane,

- elasto-plastic stress/strain relationships for concrete and reinforcing steel are used,

- the tensile strength of concrete is ignored,

- the ultimate strains for concrete are determined as $\epsilon_{c u}$ and for reinforcing steel as $\epsilon_{s u}$.

In Fig. 11, the following notation is used: $t, b-$ the thickness and the width of the cross-section, respectively, $t_{1}, t_{2}$ - coordinates describing the locations of rebars, $x, x^{\prime}$ - coordinates describing the location of the neutral axis and the location of any point of the section, respectively. In accordance with the Eurocode 2 33], the stress-strain relation for concrete $\sigma_{c}$ $-\epsilon_{c}$ in compression for a short term uniaxial loading is assumed as

$$
\sigma_{c}=\frac{k \eta_{c}-\eta_{c}^{2}}{1+(k-2) \eta_{c}} f_{c m},
$$

where: $\eta_{c}=\epsilon_{c} / \epsilon_{c 1}, \epsilon_{c 1}$ - the strain at peak stress on the $\sigma_{c}-\epsilon_{c}$ diagram, $k=1.05 E_{c m}\left|\epsilon_{c 1}\right| / f_{c m}, f_{c m}$ - the mean compressive strength of concrete, $E_{c m}$ secant modulus of elasticity of concrete, $\epsilon_{c u}\left(\epsilon_{c u 1}\right)-$ the ultimate strain for concrete.

The reinforcing steel is characterized by yield stress $f_{y k}, E_{s}$ - modulus of elasticity and $E_{h}$ - coefficient of steel hardening (linear elastic model with hardening).

\subsection{Equations For StRAins IN THE RECTANGULAR SECTIONS}

In further considerations, the corresponding dimensionless coordinates are used:

$$
\xi=x / t, \quad \xi^{\prime}=x^{\prime} / t, \quad \xi_{1}=t_{1} / t, \quad \xi_{2}=t_{2} / t .
$$

\subsubsection{EQUATIONS FOR SECTIONS WhOLLY IN COMPRESSION}

Let us consider the section wholly in compression. The strain distribution can be expressed in the form

$$
\epsilon=\epsilon_{1}+\left(\epsilon_{2}-\epsilon_{1}\right) \xi^{\prime},
$$

where:

$$
\begin{aligned}
\epsilon_{1} & -\quad \text { maximum compressive strain } \\
& \text { in the cross section, } \\
\epsilon_{2}- & \text { minimum compressive strain } \\
& \text { in the cross section. }
\end{aligned}
$$

Thus, $\eta_{c}$ occuring in (1) assumes the form

$$
\eta_{c}=k_{2} \xi^{\prime}+k_{1},
$$

after including in (3) the following assignements: $k_{1}=$ $\frac{\epsilon_{1}}{\epsilon_{c 1}}$ and $k_{2}=\frac{\epsilon_{2}-\epsilon_{1}}{\epsilon_{c 1}}$.

The equilibrium equation of the axial forces in the cross-section takes the following form

$$
\int_{A_{c}} \sigma_{c} d A_{c}+\sigma_{s 1} F_{a 1}+\sigma_{s 2} F_{a 2}+N=0
$$

where: $d A_{c}$ - element of the concrete area $A_{c}, F_{a 1}$, $F_{a 2}$ - areas of the steel in compression and in tension, respectively.

The sectional equilibrium of the bending moments about the symmetry axis of the rectangle can be expressed in the form

$$
\begin{gathered}
\int_{A_{c}} \sigma_{c}\left(0.5 t-x^{\prime}\right) d A_{c}+\sigma_{s 1} F_{a 1}\left(0.5 t-t_{1}\right)+ \\
\sigma_{s 2} F_{a 2}\left(0.5 t-t_{2}\right)-M=0 .
\end{gathered}
$$

In order to obtain the final form of the equilibrium equations, we integrated formulas in (5) and (6). The 
most difficult part was to find the antiderivatives of the functions in the integral expressions in (5) and (6). After substituting relations (3) and (4) in relation (1), the function to be integrated in (5) is

$$
f_{N}\left(\xi^{\prime}\right)=\frac{k\left(k_{2} \xi^{\prime}+k_{1}\right)-\left(k_{2} \xi^{\prime}+k_{1}\right)^{2}}{1+(k-2)\left(k_{2} \xi^{\prime}+k_{1}\right)}
$$

and in (6) is

$$
f_{M}\left(\xi^{\prime}\right)=\frac{k\left(k_{2} \xi^{\prime}+k_{1}\right)-\left(k_{2} \xi^{\prime}+k_{1}\right)^{2}}{1+(k-2)\left(k_{2} \xi^{\prime}+k_{1}\right)}\left(0.5-\xi^{\prime}\right) .
$$

Finally, the following equilibrium equations for strains in the rectangular sections are found. The first one concerns the equilibrium equation of the axial forces

$$
\begin{aligned}
& n+\frac{1}{k-2}\left\{W_{1}+0.5 k_{2}+\frac{W_{2}}{W_{3}}\left(\ln W_{5}-\ln W_{6}\right)\right\}+ \\
& \mu_{1} \frac{f_{y k}}{f_{c m}}\left\{\delta _ { i 1 } \left[-1+\frac{E_{h}}{f_{y k}}\left(\left(\left(\epsilon_{2}-\epsilon_{1}\right) \xi_{1}+\epsilon_{1}\right)+\right.\right.\right. \\
& \left.\left.\left.\epsilon_{s s}\right)\right]+\delta_{i 1+1} \frac{\left(\epsilon_{2}-\epsilon_{1}\right) \xi_{1}+\epsilon_{1}}{\epsilon_{s s}}\right\}+ \\
& \mu_{2} \frac{f_{y k}}{f_{c m}}\left\{\delta _ { i 2 } \left[1+\frac{E_{h}}{f_{y k}}\left[\left(\left(\epsilon_{2}-\epsilon_{1}\right)\left(1-\xi_{2}\right)+\epsilon_{1}\right)-\right.\right.\right. \\
& \left.\left.\epsilon_{s s}\right]\right] \\
& \left.+\delta_{i 2+1} \frac{\left(\epsilon_{2}-\epsilon_{1}\right)\left(1-\xi_{2}\right)+\epsilon_{1}}{\epsilon_{s s}}\right\}=0
\end{aligned}
$$

and the second one represents the sectional equilibrium of the bending moments

$$
\begin{aligned}
& -m+\frac{1}{k-2}\left\{-\frac{k_{2}}{12}+0.5 \frac{W_{2}}{W_{6}}\left(\ln W_{5}-\ln W_{6}\right)\right. \\
& \left.-\frac{W_{2}}{W_{3}}\left[1-\frac{W_{6}}{W_{4}}\left(\ln W_{5}-\ln W_{6}\right)\right]\right\}+ \\
& \mu_{1} \frac{f_{y k}}{f_{c m}}\left(0.5-\xi_{1}\right)\left\{\delta _ { i 1 } \left[1+\frac{E_{h}}{f_{y k}}\left(\left(\left(\epsilon_{2}-\epsilon_{1}\right) \xi_{1}+\epsilon_{1}\right)+\right.\right.\right. \\
& \left.\left.\left.\epsilon_{s s}\right)\right]+\delta_{i 1+1} \frac{\left(\epsilon_{2}-\epsilon_{1}\right) \xi_{1}+\epsilon_{1}}{\epsilon_{s s}}\right\}+ \\
& \mu_{2} \frac{f_{y k}}{f_{c m}}\left(0.5-\xi_{2}\right)\left\{\delta _ { i 2 } \left[1+\frac{E_{h}}{f_{y k}}\left(\left(\left(\epsilon_{2}-\epsilon_{1}\right)\left(1-\xi_{2}\right)+\right.\right.\right.\right. \\
& \left.\left.\left.\left.\epsilon_{1}\right)-\epsilon_{s s}\right)\right]+\delta_{i 2+1} \frac{\left(\epsilon_{2}-\epsilon_{1}\right)\left(1-\xi_{2}\right)+\epsilon_{1}}{\epsilon_{s s}}\right\}=0
\end{aligned}
$$

where:

$$
\begin{array}{l|l}
W_{1}=k_{1}-k-\frac{1}{k-2} & W_{2}=k(k-2)+1 \\
W_{3}=(k-2)(k-2) k_{2} & W_{4}=(k-2) k_{2} \\
W_{5}=1+\frac{k-2}{k_{2}+k_{1}} & n=\frac{N}{b t f_{c m}} \\
W_{6}=1+(k-2)\left(k_{2}+k_{1}\right) & m=\frac{M}{b t^{2} f_{c m}} \\
\delta_{i}=0.5\left(\left(-1^{i}\right)+1\right), \quad i=1,2 &
\end{array}
$$

and: $\mu_{1}$ - the reinforcement ratio of steel in compression, $\mu_{2}$ - the reinforcement ratio of steel in tension. The unknown variables are: $\epsilon_{1}, \epsilon_{2}$.

\subsubsection{SECTION UNDER COMBINED COMPRESSION WITH BENDING}

Let us consider the section under combined compression and bending. Due to the Bernoulli assumption, one obtains (see Fig. 1 )

$$
\epsilon=\left(1-\frac{\xi^{\prime}}{\xi}\right) \epsilon^{\prime}
$$

where: $\epsilon^{\prime}-$ the maximum compressive strain in concrete.

The resulting formulas are given below. Equation (12) (for axial forces)

$$
\begin{aligned}
& n+\frac{1}{k-2}\left\{W_{1} \xi+0.5 k_{2} \xi^{2}-\frac{1}{k-2}\left[\frac{W_{2}}{W_{3}} \ln W-\xi\right]\right\}+ \\
& \mu_{1} \frac{f_{y k}}{f_{c m}}\left\{\delta_{i 1}\left[-1+\frac{E_{h}}{f_{y k}}\left(\left(1-\frac{\xi_{1}}{\xi}\right) \epsilon^{\prime}+\epsilon_{s s}\right)\right]\right. \\
& \left.+\delta_{i 1+1} \frac{\epsilon^{\prime}}{\epsilon_{s s}}\left(1-\frac{\xi_{1}}{\xi}\right)\right\}+ \\
& \mu_{2} \frac{f_{y k}}{f_{c m}}\left\{\delta_{i 2}\left[+1+\frac{E_{h}}{f_{y k}}\left(\left(1-\frac{1-\xi_{2}}{\xi}\right) \epsilon^{\prime}-\epsilon_{s s}\right)\right]\right. \\
& \left.+\delta_{i 2+1} \frac{\epsilon^{\prime}}{\epsilon_{s s}}\left(1-\frac{1-\xi_{2}}{\xi}\right)\right\}=0
\end{aligned}
$$

and equation (13), representing the sectional equilibrium of the bending moments

$$
\begin{aligned}
& -m+\frac{1}{k-2}\left\{0.5\left(W_{1}+\frac{1}{k-2}\right) \xi+\right. \\
& 0.5\left[-W_{1}+0.5 k_{2}-\frac{1}{k-2}\right] \xi^{2}- \\
& \left.\frac{1}{3} k_{2} \xi^{3}-\frac{W_{2}}{(k-2) W_{3}}\left[0.5 \ln W+\xi-\frac{W}{W_{3}} \ln W\right]\right\}+ \\
& \mu_{1} \frac{f_{y k}}{f_{c m}}\left(0.5-\xi_{1}\right)\left\{\delta_{i 1}\left[1+\frac{E_{h}}{f_{y k}}\left(\left(1-\frac{\xi_{1}}{\xi}\right) \epsilon^{\prime}+\epsilon_{s s}\right)\right]\right. \\
& \left.+\delta_{i 1+1} \frac{\epsilon^{\prime}}{\epsilon_{s s}}\left(1-\frac{\xi_{1}}{\xi}\right)\right\}+ \\
& \mu_{2} \frac{f_{y k}}{f_{c m}}\left(0.5-\xi_{2}\right)\left\{\delta _ { i 2 } \left[+1+\frac{E_{h}}{f_{y k}}\left(\left(1-\frac{1-\xi_{2}}{\xi}\right) \epsilon^{\prime}-\right.\right.\right. \\
& \left.\left.\left.\epsilon_{s s}\right)\right]+\delta_{i 2+1} \frac{\epsilon^{\prime}}{\epsilon_{s s}}\left(1-\frac{1-\xi_{2}}{\xi}\right)\right\} \\
& =0
\end{aligned}
$$

where:

$$
\begin{array}{l|l}
W_{1}=k-k_{2} \xi & W_{2}=k(k \\
W_{3}=(k-2) k_{2} & W=1+(k \\
\delta_{i}=0.5\left((-1)^{i}+1\right), \quad i=1,2 & k_{2}=\frac{\epsilon^{\prime}}{\epsilon_{c 1} \xi}
\end{array}
$$

The unknown variables are:

- $\epsilon^{\prime}-$ maximum strain in the cross section,

- $\xi$ - coordinate describing the location of the neutral axis.

\section{Computational solution And NUMERICAL RESULTS}

It is not our first work with models of the processes in the RC structure members. We have already got some experience with the circular RC structure members [6]. This experience suggests that we have to 
expect many global and local solutions of the least squares problem. Therefore, we decided to compare three different algorithms: local search method (trust region reflective) started many times from all points from a net of points equally distributed on the feasible box and genetic and particle swarm algorithms designed for searching a global optimum.

For the verification of the obtained formulae, two rectangular cross-sections $0.3 \mathrm{~m} \times 0.3 \mathrm{~m}$ under the compression have been considered: the unreinforced one and that of reinforced $\left(\mu f_{y k} / f_{c m}=0.1\right)$. Both sections had the following characteristics: the concrete grade $C 20 / 25$, the yield stress of steel $f_{y k}=500 M P a$ (reinforced), reinforcement ratios of the steel in compression and in tension $\mu_{1}=\mu_{2}=\mu, t_{1} / t=t_{2} / t=0.1$, $E_{h}=0$. It is assumed that the resistance of the cross-section is reached when the compressive strain in concrete $\epsilon_{c u}=-3.5 \%$ or the ultimate strain in the reinforcing steel equals $\epsilon_{s u}=10 \%$. After some rearrangements and substituting $\epsilon^{\prime}=x$ and $\xi=y$, the set of equations 12,13 takes the forms 14,15 for the unreinforced and (16 17) for the reinforced cross-sections, respectively.

Due to the appearance of the term $y-x$ in the denominator in some sets of equations, a danger of the division by 0 occurs. For this reason, fmincon has been finally applied with the algorithm option set to "interior point method", that allowed to include special constraints eliminating this danger. Moreover, the existence of multiple minima may not be avoided. However, the least squares formulation of the problem itself may, in general, involve extra local solutions (such a counterexample may be found in Stachurski [34]). This has been confirmed through computational results. Many local minima and sometimes several global minima that resulted from the numerical properties of the optimization problem were encountered. Therefore, the clusterization idea imported from clusterization the methods of the global optimization was incorporated (see, for instance, Thorn and Żilinstas [35]). The size of the problem and computation time were of secondary importance. We have also tested the genetic and particle swarm algorithms from the global optimization Matlab's toolbox, comparing them with a local search method started from all points of the net covering the whole set $\Omega$ of feasible points. For testing purposes, the sets of equations were used that described the reinforced or unreinforced concrete sections subjected to the compression.

The equations for the concrete without the reinforcement - the subject to the compression with bending are

$$
\begin{aligned}
& r_{1}(x, y)=-a_{1}+(2.25+0.5 x) y- \\
& \quad 0.25 x y- \\
& \quad 4\left[-12.5 \frac{y}{x} \ln (1-0.125 x)-y\right]=0,
\end{aligned}
$$

$$
\begin{aligned}
& r_{2}(x, y)=-a_{2}+(3.125+0.25 x) y+ \\
& \quad\left[-3.125+0.25 x-0.125 \frac{x}{y}\right] y^{2}+ \\
& 0.16667 x y^{2}+ \\
& \quad 50 \frac{y}{x}[0.5 \ln (1-0.125 x)+y+ \\
& \left.\quad 8 \frac{(1-0.125 x) y}{x} \ln (1-0.125 x)\right] \\
& \quad=0
\end{aligned}
$$

where:

$$
\begin{array}{ll}
x \text { - } & \text { maximum compressive } \\
& \text { strain in concrete } \\
y \text { - } & \text { coordinate specifying } \\
& \text { location of the neutral } \\
& \text { axis of the cross-section }
\end{array}
$$

Different values of constants $a_{1}$ and $a_{2}$ correspond to different axial forces $N$ and bending moments $M$. Parameters a are collected in table 1

The corresponding equations for the reinforced concrete section subjected to the compression with bending are given below

$$
\begin{gathered}
r_{1}(x, y)=(2.25+0.5 x) y-0.25 x y- \\
4\left[-12.5 \frac{y}{x} \ln (1-0.125 x)-y\right]+ \\
0.01 x\left(1-\frac{0.9}{y}\right)-a_{1}=0, \\
r_{2}(x, y)=(3.125+0.25 x) y- \\
\quad\left[3.125+0.25 x+0.125 \frac{x}{y}\right] y^{2}+ \\
0.16667 x y^{2}+\quad \\
50 \frac{y}{x}[0.5 \ln (1-0.125 x)+y+ \\
\left.8(1-0.125 x) \frac{y}{x} \ln (1-0.125 x)\right]+ \\
0.004 x\left(1-\frac{0.9}{y}\right)-a_{2}=0,
\end{gathered}
$$

where $x$ and $y$ have the same meaning and scope as in equations (14) and (15).

We used two sets of constant parameters $a_{1}$ and $a_{2}$ for that case specified below.

\begin{tabular}{ccc}
\hline Set No. & $a_{1}$ & $a_{2}$ \\
\hline 1 & 0.143445 & 0.0292155 \\
2 & 0.129182 & 0.0348055 \\
\hline
\end{tabular}

We have to solve sets of two nonlinear equations with two unknowns $x$ and $y$ specified above

$$
\begin{aligned}
& \left\{\begin{array}{l}
r_{1}(x, y)=0 \\
r_{2}(x, y)=0
\end{array} \text { where }\left[\begin{array}{l}
x \\
y
\end{array}\right] \in \Omega\right. \\
& \Omega=\left\{\left[\begin{array}{l}
x \\
y
\end{array}\right] \in R^{2} \mid \begin{array}{l}
x^{L} \leq x \leq x^{U} \\
y^{L} \leq y \leq y^{U}
\end{array}\right\}
\end{aligned}
$$

$x^{L}, x^{U}$ are the lower bound and upper bound on variable $x$ and similarly $y^{L}, y^{U}$ are the lower bound and upper bound on variable $y$. Due to their presence, a direct use of numerical methods for solving sets of nonlinear equations seems to be impractical.

Therefore, our task was reformulated by means of the frequently used the least squares method. It has 


\begin{tabular}{ccc}
\hline Set No. & $a_{1}$ & $a_{2}$ \\
\hline 1 & 0.17157 & 0.01717 \\
2 & 0.13345 & 0.02522 \\
3 & 0.10918 & 0.026805 \\
4 & 0.08579 & 0.02574 \\
5 & 0.07065 & 0.02369 \\
6 & 0.04448 & 0.01763 \\
7 & 0.02571 & 0.01138 \\
\hline
\end{tabular}

TABLE 1. Sets of parameters for unreinforced concrete subjected to compression with bending

lead to a nonlinear, nonconvex optimization problem

$$
\begin{array}{ll}
\min _{(x, y)} & f(x, y)=\frac{1}{2}\left(r_{1}^{2}(x, y)+r_{2}^{2}(x, y)\right) \\
& \\
\text { s.t. } & x^{L} \leq x \leq x^{U} \\
& y^{L} \leq y \leq y^{U}
\end{array}
$$

Below are given the results of the local search with multiple starting points, genetic algorithm and the particle swarm optimization method.

In the first approach, we selected the fmincon function from the MATLAB Optimization Toolbox as a tool to solve the least squares problem $(19)$, because it allows the introduction of of the box constraints.

The steps of the procedure may be summarized as follows:

Set $S$ - set of solution clusters to be an empty set. while (there are non used points in the net cover$\operatorname{ing} \Omega$ )

- take a new point $\mathbf{x}^{0} \in \Omega$,

- solve the least squares problem by means of the fmincon function from the MATLAB's toolbox OPTIMIZATION starting from the point $\mathbf{x}^{0}$,

- denote the found solution by $x$,

- if $f(x)<$ restOL

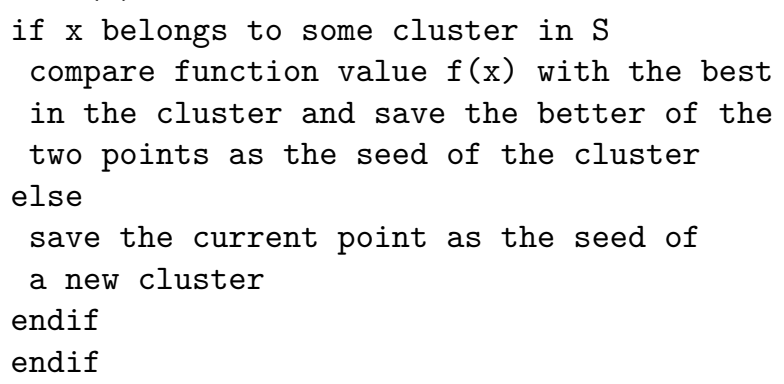

We assumed the threshold value $\operatorname{resTOL}=1.0 e-20$. The only exception was the set of sample problems for the reinforced concrete section subjected to the compression with bending where resTOL $=1.0 e-$ 10. In the clusterization, we treated a new point as a structure member of the cluster if the following inequality was verified

$$
\left\|\hat{\mathbf{x}}-\mathbf{x}_{\text {seed }}\right\| \leq \operatorname{distTOL}
$$

where $\mathbf{x}_{\text {seed }}$ is the seed point of the current cluster. We assumed distTOL $=1.0 e^{-10}$.
The need of the clusterization is fully justified by the table 2 presented below.

We can evidently observe four different clusters in the table.

First seven examples are connected with the concrete sections without reinforcement. They are subjected to compression and bending. Parameters a are collected in table 1 and the calculated solutions are put to table 3

Consecutive table 4 contains the solutions for two sets associated with the situation, when the sections are reinforced.

The results of calculations with the genetic algorithm are summarized in table 5 (for the sections without reinforcement) and in table 6] (for sections with reinforcement). Unfortunately, the implementation of the genetic algorithm from the Matlab's global optimization toolbox has found only one global solution, even for sets where the local minimizer detected more global solutions. Furthermore, the accuracy of the ga solution is definitely poorer compared with that found by the local minimizer.

Tables 7 and 8 summarize the results obtained by means of the particle swarm algorithm implementation in the Matlab's global optimization toolbox. The same comment as for the ga Matlab function is valid for the particle swarm one.

\section{Comparison of EXPERIMENTAL AND NUMERICAL RESULTS}

In order to verify the calculated results, $175 \mathrm{~mm} \times$ $175 \mathrm{~mm} \times 1680 \mathrm{~mm}$ (the height) column specimens under eccentric compression were considered, the results of which were presented in detail by Lloyd at al. [16]. The longitudinal steel reinforcement of the columns consisted of three rebars $\phi 12 \mathrm{~mm}, f_{y k}=430$ $\mathrm{MPa}, E_{s}=200 \mathrm{GPa}$ and they were made of concrete $f_{c m}=44.78 \mathrm{MPa}, E_{c m}=32 \mathrm{GPa}$. The static diagram and test specimen are shown in Fig. 2 In the above mentioned tests, the following failure loads and corresponding eccentricities were measured: $P_{1}=1476 \mathrm{kN}$, $e_{1}=15 \mathrm{~mm} ; P_{2}=830 \mathrm{kN}, e_{2}=50 \mathrm{~mm} ; P_{3}=660$ $\mathrm{kN}, e_{3}=65 \mathrm{~mm}$. The ultimate strain in concrete at failure was assumed in calculations as $-2.4 \%$, which corresponds to the peak stress on the $\sigma_{c}-\epsilon_{c}$ diagram (Fig. 1). The values collected in table 9 confirm a good 


\begin{tabular}{ccc}
\hline $\mathrm{x}(1)$ & $\mathrm{x}(2)$ & $\mathrm{f}(\mathrm{x})$ \\
\hline$-2.7790923390672915 \mathrm{e}+00$ & $-3.0371456600817055 \mathrm{e}+00$ & $9.8607613152626476 \mathrm{e}-32$ \\
$-2.7790923390376046 \mathrm{e}+00$ & $-3.0371456601087723 \mathrm{e}+00$ & $2.2186712959340957 \mathrm{e}-29$ \\
$-3.5000157890703703 \mathrm{e}+00$ & $-4.9999510298477368 \mathrm{e}-01$ & $1.2325951644078309 \mathrm{e}-29$ \\
$-2.7790923390051390 \mathrm{e}+00$ & $-3.0371456601383064 \mathrm{e}+00$ & $9.1507865005637369 \mathrm{e}-29$ \\
$-2.7790923391531197 \mathrm{e}+00$ & $-3.0371456600033153 \mathrm{e}+00$ & $1.9721522630525295 \mathrm{e}-29$ \\
$-2.7790923392382747 \mathrm{e}+00$ & $-3.0371456599104514 \mathrm{e}+00$ & $8.4692264556708872 \mathrm{e}-25$ \\
$-1.2763043306571440 \mathrm{e}+00$ & $-1.0595130305186657 \mathrm{e}+00$ & $4.9303806576313238 \mathrm{e}-31$ \\
$-1.2763043306472746 \mathrm{e}+00$ & $-1.0595130305290790 \mathrm{e}+00$ & $6.9364539396083568 \mathrm{e}-27$ \\
$-2.7790923389334106 \mathrm{e}+00$ & $-3.0371456602237172 \mathrm{e}+00$ & $5.7569619331116098 \mathrm{e}-25$ \\
$-1.2763043307376327 \mathrm{e}+00$ & $-1.0595130304452089 \mathrm{e}+00$ & $4.7302072029314920 \mathrm{e}-28$ \\
$-1.2763043305691497 \mathrm{e}+00$ & $-1.0595130306000431 \mathrm{e}+00$ & $2.0523202525456148 \mathrm{e}-27$ \\
$-6.2452876553920056 \mathrm{e}-01$ & $-3.6491369858491312 \mathrm{e}+00$ & $3.6484816866471796 \mathrm{e}-30$ \\
\hline
\end{tabular}

TABLE 2. Sample table of results without clusterization

\begin{tabular}{|c|c|c|}
\hline $\mathrm{x}(1)$ & $\mathrm{x}(2)$ & $\mathrm{f}$ \\
\hline \multicolumn{3}{|c|}{ Set 1} \\
\hline \multicolumn{3}{|c|}{$\mathrm{a}(1)=1.7157000000000000 \mathrm{e}-01 \quad \mathrm{a}(2)=1.7170000000000001 \mathrm{e}-02$} \\
\hline$-3.5001760272980009 \mathrm{e}+00$ & $8.9999746818148496 \mathrm{e}-01$ & $1.6308774769071113 \mathrm{e}-29$ \\
\hline \multicolumn{3}{|c|}{ Set 2} \\
\hline \multicolumn{3}{|c|}{$\mathrm{a}(1)=1.3345000000000001 \mathrm{e}-01 \quad \mathrm{a}(2)=2.5219999999999999 \mathrm{e}-02$} \\
\hline$-3.4992749633586557 \mathrm{e}+00$ & $6.9999666861370502 \mathrm{e}-01$ & $1.9772367181057118 \mathrm{e}-29$ \\
\hline$-1.7538910914819157 \mathrm{e}+00$ & $8.3132002867829691 \mathrm{e}-01$ & $4.3364238627823002 \mathrm{e}-29$ \\
\hline \multicolumn{3}{|c|}{ Set 3} \\
\hline \multicolumn{3}{|c|}{$\mathrm{a}(1)=1.0918000000000000 \mathrm{e}-01 \quad \mathrm{a}(2)=2.6804999999999999 \mathrm{e}-02$} \\
\hline$-3.5000264028206489 \mathrm{e}+00$ & $5.7271595174704082 \mathrm{e}-01$ & $8.1807341061747740 \mathrm{e}-29$ \\
\hline$-1.7532806514095229 \mathrm{e}+00$ & $6.8025870700809510 \mathrm{e}-01$ & $2.0954117794933126 \mathrm{e}-29$ \\
\hline \multicolumn{3}{|c|}{ Set 4} \\
\hline \multicolumn{3}{|c|}{$\mathrm{a}(1)=8.5790000000000005 \mathrm{e}-02 \quad \mathrm{a}(2)=2.5739999999999999 \mathrm{e}-02$} \\
\hline$-3.4999421856987043 e+00$ & $4.5001889527019823 \mathrm{e}-01$ & $2.6437933681383566 \mathrm{e}-28$ \\
\hline$-1.7533490610068840 \mathrm{e}+00$ & $5.3451336316461950 \mathrm{e}-01$ & $2.9496002284279395 \mathrm{e}-29$ \\
\hline \multicolumn{3}{|c|}{ Set 5} \\
\hline \multicolumn{3}{|c|}{$\mathrm{a}(1)=7.0650000000000004 \mathrm{e}-02 \quad \mathrm{a}(2)=2.3689999999999999 \mathrm{e}-02$} \\
\hline$-3.5002461261714624 \mathrm{e}+00$ & $3.7060720525856033 \mathrm{e}-01$ & $6.1800472650662032 \mathrm{e}-28$ \\
\hline$-1.7531021761012342 \mathrm{e}+00$ & $4.4021717424283136 \mathrm{e}-01$ & $4.8915539099524771 \mathrm{e}-29$ \\
\hline \multicolumn{3}{|c|}{ Set 6} \\
\hline \multicolumn{3}{|c|}{$\mathrm{a}(1)=4.4479999999999999 \mathrm{e}-02 \quad \mathrm{a}(2)=1.7630000000000000 \mathrm{e}-02$} \\
\hline$-3.4981410371676795 \mathrm{e}+00$ & $2.3329954055348942 \mathrm{e}-01$ & $3.9372571632525573 \mathrm{e}-27$ \\
\hline$-1.7548124428383809 \mathrm{e}+00$ & $2.7700765058540189 \mathrm{e}-01$ & $8.0396019598500773 \mathrm{e}-29$ \\
\hline \multicolumn{3}{|c|}{ Set 7} \\
\hline \multicolumn{3}{|c|}{$\mathrm{a}(1)=2.5710000000000000 \mathrm{e}-02 \quad \mathrm{a}(2)=1.1379999999999999 \mathrm{e}-02$} \\
\hline$-3.2265678368900650 \mathrm{e}+00$ & $1.3352149291135310 \mathrm{e}-01$ & $4.2148274638856933 \mathrm{e}-26$ \\
\hline$-1.9823327248432530 \mathrm{e}+00$ & $1.5060554010027433 \mathrm{e}-01$ & $2.5005850693336105 \mathrm{e}-28$ \\
\hline
\end{tabular}

TABLE 3. Results for non-reinforced concrete subjected to compression with bending 


\begin{tabular}{ccc}
\hline $\mathrm{x}(1)$ & $\mathrm{x}(2)$ & $\mathrm{f}$ \\
$\mathrm{a}(1)=1.4344499999999999 \mathrm{e}-01$ & $\mathrm{a}(2)=2.9215499999999998 \mathrm{e}-02$ \\
$-2.2782425251491150 \mathrm{e}+00$ & $7.7232501367591999 \mathrm{e}-01$ & $2.2709743058168710 \mathrm{e}-29$ \\
$-3.4999345396782120 \mathrm{e}+00$ & $6.9999699585013297 \mathrm{e}-01$ & $3.2106687592596898 \mathrm{e}-29$ \\
$-3.4997710707333067 \mathrm{e}+00$ & $6.9999415656504049 \mathrm{e}-01$ & $6.6164575189148840 \mathrm{e}-13$ \\
\hline \multicolumn{4}{c}{ Set 2} \\
$\mathrm{a}(1)=1.2918199999999999 \mathrm{e}-01$ & $\mathrm{a}(2)=3.4805500000000003 \mathrm{e}-02$ \\
$-2.8855483058111950 \mathrm{e}+00$ & $5.9743506676707159 \mathrm{e}-01$ & $5.7336006495255961 \mathrm{e}-30$ \\
$-3.4999204514197872 \mathrm{e}+00$ & $5.7272335751221370 \mathrm{e}-01$ & $3.6503587461192280 \mathrm{e}-28$ \\
$-2.8894696731050842 \mathrm{e}+00$ & $5.9713482908132576 \mathrm{e}-01$ & $4.5482057578604896 \mathrm{e}-11$ \\
$-2.8850298075074248 \mathrm{e}+00$ & $5.9747474535630740 \mathrm{e}-01$ & $8.0528227557234545 \mathrm{e}-13$ \\
$-2.8819290341073800 \mathrm{e}+00$ & $5.9771169963840232 \mathrm{e}-01$ & $3.9597006753181514 \mathrm{e}-11$ \\
\hline
\end{tabular}

TABLE 4. Results for reinforced concrete subjected to compression with bending

\begin{tabular}{ccc}
\hline $\mathrm{x}(1)$ & $\mathrm{x}(2)$ & $\mathrm{f}$ \\
\hline \multicolumn{3}{c}{ Set 1} \\
$\mathrm{a}(1)=1.7157000000000000 \mathrm{e}-01$ & $\mathrm{a}(2)=1.7170000000000001 \mathrm{e}-02$ \\
$-2.0055257755736533 \mathrm{e}+00$ & $9.9999993722360547 \mathrm{e}-01$ & $4.9367829047643648 \mathrm{e}-06$ \\
\hline
\end{tabular}

\section{Set 2}

$\mathrm{a}(1)=1.3345000000000001 \mathrm{e}-01 \quad \mathrm{a}(2)=2.5219999999999999 \mathrm{e}-02$

\begin{tabular}{ccc}
$-1.7533927171625709 \mathrm{e}+00$ & $8.3145002503412480 \mathrm{e}-01$ & $1.1683502858156642 \mathrm{e}-11$ \\
\hline & Set 3 \\
$\mathrm{a}(1)=1.0918000000000000 \mathrm{e}-01 \quad \mathrm{a}(2)=2.6804999999999999 \mathrm{e}-02$ \\
$-3.5000168287943323 \mathrm{e}+00$ & $5.7271604685964617 \mathrm{e}-01 \quad 4.2733490746564677 \mathrm{e}-15$
\end{tabular}

Set 4

$\mathrm{a}(1)=8.5790000000000005 \mathrm{e}-02 \quad \mathrm{a}(2)=2.5739999999999999 \mathrm{e}-02$ $-3.5000605612775848 \mathrm{e}+00 \quad 4.5002358354890987 \mathrm{e}-01 \quad 1.0830715796115672 \mathrm{e}-13$

\begin{tabular}{|c|c|c|}
\hline \multicolumn{3}{|c|}{ Set 5} \\
\hline $\mathrm{a}(1)=7.065000000$ & $000004 \mathrm{e}-02 \quad \mathrm{a}(2)=2.368$ & $999999999999 \mathrm{e}-02$ \\
\hline$-1.7531661968763803 e+00$ & $4.4020811931145998 \mathrm{e}-01$ & $1.4944588897123600 \mathrm{e}-14$ \\
\hline \multicolumn{3}{|c|}{ Set 6} \\
\hline \multicolumn{3}{|c|}{$\mathrm{a}(1)=4.4479999999999999 \mathrm{e}-02 \quad \mathrm{a}(2)=1.7630000000000000 \mathrm{e}-02$} \\
\hline$-3.4974023122097648 \mathrm{e}+00$ & $2.3328811178613765 \mathrm{e}-01$ & $1.9405016478273012 \mathrm{e}-13$ \\
\hline \multicolumn{3}{|c|}{ Set 7} \\
\hline \multicolumn{3}{|c|}{$\mathrm{a}(1)=2.5710000000000000 \mathrm{e}-02 \quad \mathrm{a}(2)=1.1379999999999999 \mathrm{e}-02$} \\
\hline$-3.8846165545827720 \mathrm{e}+00$ & $1.3993640821435832 \mathrm{e}-01$ & $1.8945631674275027 \mathrm{e}-08$ \\
\hline
\end{tabular}

TABlE 5. Results for non-reinforced concrete subjected to compression with bending obtained by Matlab's genetic algorithm function

\begin{tabular}{ccc}
\hline $\mathrm{x}(1)$ & $\mathrm{x}(2)$ & $\mathrm{f}$ \\
\hline \multicolumn{4}{c}{ Set 1} \\
$\mathrm{a}(1)=1.4344499999999999 \mathrm{e}-01 \quad \mathrm{a}(2)=2.9215499999999998 \mathrm{e}-02$ \\
$-2.2782188146226554 \mathrm{e}+00$ & $7.7232945260092078 \mathrm{e}-01$ & $1.9240836428670515 \mathrm{e}-14$ \\
\hline \multicolumn{4}{c}{ Set 2} \\
$\mathrm{a}(1)=1.2918199999999999 \mathrm{e}-01 \quad \mathrm{a}(2)=3.4805500000000003 \mathrm{e}-02$ \\
$-2.8837525833446813 \mathrm{e}+00$ & $5.9758208926874357 \mathrm{e}-01$ & $1.0366597163520163 \mathrm{e}-11$ \\
\hline
\end{tabular}

TABLE 6. Results for reinforced concrete subjected to compression with bending obtained by Matlab's genetic algorithm function 


\begin{tabular}{|c|c|c|}
\hline $\mathrm{x}(1)$ & $\mathrm{x}(2)$ & $\mathrm{f}$ \\
\hline \multicolumn{3}{|c|}{ Set 1} \\
\hline \multicolumn{2}{|c|}{$\mathrm{a}(1)=1.7157000000000000 \mathrm{e}-01$} & \multirow{2}{*}{$\begin{array}{c}\mathrm{a}(2)=1.7170000000000001 \mathrm{e}-02 \\
1.1469551926718323 \mathrm{e}-10\end{array}$} \\
\hline$-3.5002095622539371 \mathrm{e}+00$ & $8.9992251419894265 \mathrm{e}-01$ & \\
\hline \multicolumn{3}{|c|}{ Set 2} \\
\hline $\mathrm{a}(1)=1.334500$ & $000000001 \mathrm{e}-01$ & \multirow{2}{*}{$\begin{array}{c}\mathrm{a}(2)=2.5219999999999999 \mathrm{e}-02 \\
8.0833419633913090 \mathrm{e}-12\end{array}$} \\
\hline$-3.4988243017354601 \mathrm{e}+00$ & $6.9999134440783828 \mathrm{e}-01$ & \\
\hline \multicolumn{3}{|c|}{ Set 3} \\
\hline $\mathrm{a}(1)=1.091800$ & 000000000e-01 & \multirow{2}{*}{$\begin{array}{c}\mathrm{a}(2)=2.6804999999999999 \mathrm{e}-02 \\
9.7034824624575985 \mathrm{e}-12\end{array}$} \\
\hline$-3.5005599263496445 \mathrm{e}+00$ & $5.7271548379815385 \mathrm{e}-01$ & \\
\hline \multicolumn{3}{|c|}{ Set 4} \\
\hline $\mathrm{a}(1)=8.579000$ & 000000005e-02 & \multirow{2}{*}{$\begin{array}{c}\mathrm{a}(2)=2.5739999999999999 \mathrm{e}-02 \\
4.3542554256757773 \mathrm{e}-11\end{array}$} \\
\hline$-3.4996043294305919 \mathrm{e}+00$ & $4.5005795509525537 \mathrm{e}-01$ & \\
\hline \multicolumn{3}{|c|}{ Set 5} \\
\hline $\mathrm{a}(1)=7.065000$ & 000000004e-02 & \multirow{2}{*}{$\begin{array}{c}\mathrm{a}(2)=2.3689999999999999 \mathrm{e}-02 \\
3.6828714611703899 \mathrm{e}-09\end{array}$} \\
\hline$-3.5287486517409783 \mathrm{e}+00$ & $3.7098837709011562 \mathrm{e}-01$ & \\
\hline \multicolumn{3}{|c|}{ Set 6} \\
\hline $\mathrm{a}(1)=4.447999$ & 999999999e-02 & \multirow{2}{*}{$\begin{array}{c}\mathrm{a}(2)=1.7630000000000000 \mathrm{e}-02 \\
1.4855280597896296 \mathrm{e}-08\end{array}$} \\
\hline$-1.8974393623306212 \mathrm{e}+00$ & $2.6652417435303338 \mathrm{e}-01$ & \\
\hline \multicolumn{3}{|c|}{ Set 7} \\
\hline $\mathrm{a}(1)=2.571000$ & $000000000 \mathrm{e}-02$ & \multirow{2}{*}{$\begin{array}{c}\mathrm{a}(2)=1.1379999999999999 \mathrm{e}-02 \\
5.6375712128260839 \mathrm{e}-11\end{array}$} \\
\hline$-3.2244553544557881 \mathrm{e}+00$ & $1.3346506124150329 \mathrm{e}-01$ & \\
\hline
\end{tabular}

TABLE 7. Results for non-reinforced concrete subjected to compression with bending obtained by Matlab's particle swarm function

\begin{tabular}{ccc}
\hline $\mathrm{x}(1)$ & $\mathrm{x}(2)$ & $\mathrm{f}$ \\
\hline \multicolumn{4}{c}{ Set 1} \\
$\mathrm{a}(1)=1.4344499999999999 \mathrm{e}-01 \quad \mathrm{a}(2)=2.9215499999999998 \mathrm{e}-02$ \\
$-3.5011205692965111 \mathrm{e}+00$ & $6.9993319470774185 \mathrm{e}-01$ & $1.0180508409446182 \mathrm{e}-10$ \\
\hline \multicolumn{4}{c}{ Set 2} \\
$\mathrm{a}(1)=1.2918199999999999 \mathrm{e}-01 \quad \mathrm{a}(2)=3.4805500000000003 \mathrm{e}-02$ \\
$-3.5003741045884293 \mathrm{e}+00$ & $5.7271843442355697 \mathrm{e}-01$ & $8.6633784199345278 \mathrm{e}-13$ \\
\hline
\end{tabular}

TABLE 8. Results for reinforced concrete subjected to compression with bending obtained by Matlab's particle swarm function

\begin{tabular}{|c|c|c|c|c|c|}
\hline \multicolumn{2}{|c|}{ Experimental } & \multicolumn{4}{|c|}{ Numerical } \\
\hline $\begin{array}{l}\text { Failure load } P_{i}[\mathrm{kN}] \\
\text { eccentricity } e_{i}[\mathrm{~mm}]\end{array}$ & $\begin{array}{c}\epsilon_{c u}=\epsilon_{c 1} \\
{[\% 0]}\end{array}$ & $\begin{array}{c}\epsilon^{\prime} \\
{[\% 0]}\end{array}$ & $\xi$ & $\begin{array}{c}\text { strain in } \\
\text { steel } \\
\epsilon_{s}[\% 0]\end{array}$ & $\epsilon_{1} / \epsilon_{2} \quad[\%]$ \\
\hline$P_{1}=1476$ & -2.4 & -2.20 & & & $-2.20 /-0.35$ \\
\hline$P_{2}=830$ & -2.4 & -2.20 & 0.63 & 0.92 & \\
\hline$P_{3}=660$ & -2.4 & -2.20 & 0.49 & 1.85 & \\
\hline
\end{tabular}

TABLE 9. Comparison of the experimental and numerical results -1 


\begin{tabular}{lcccc}
\hline \multicolumn{2}{c}{ Experimental } & \multicolumn{2}{c}{ Numerical } \\
\hline Failure load $P_{i}[\mathrm{kN}]$ & $\epsilon_{c u}=\epsilon_{c 1}$ & $\epsilon_{1}$ & $\epsilon_{2}$ \\
eccentricity $e_{i}[\mathrm{~mm}]$ & {$[\% 0]$} & {$[\% 0]$} & {$[\% 0]$} \\
\hline$P_{1}=1548 ; \quad e_{1}=0$ & -2.1 & -2.1 & -2.1 \\
$P_{2}=1386 ; \quad e_{2}=16$ & -2.1 & -1.95 & -0.31 \\
$P_{3}=1098 ; \quad e_{3}=32$ & -2.1 & -1.95 & -0.12 \\
\hline
\end{tabular}

TABLE 10. Comparison of the experimental and numerical results

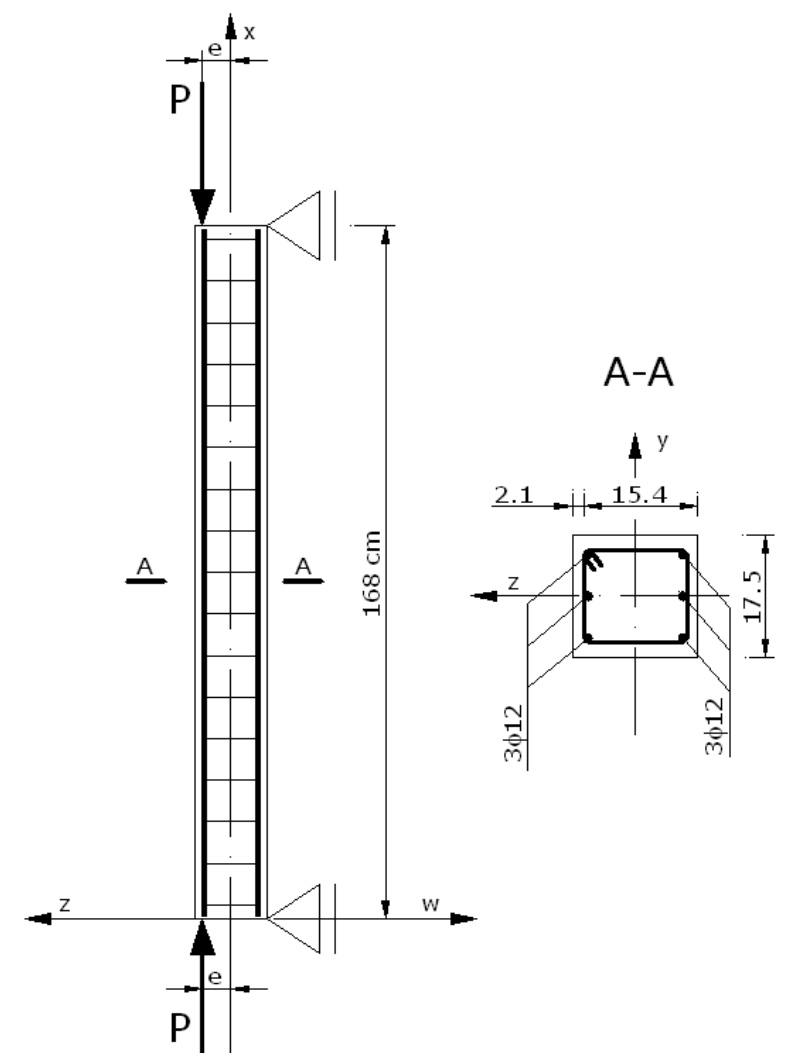

Figure 2. Static diagram and test specimen

conformity between the numerical solution and the experimental data given by Lloyd and Rangan [16]. It is worth noting that the theoretical values are lower than those obtained from the experiment due to neglecting the effect of confinement of the column.

As the next example, the results of tests conducted by Trapko at al. [20] on unstrenghtened column specimens $200 \mathrm{~mm} \times 200 \mathrm{~mm} \times 1500 \mathrm{~mm}$ (the height) under eccentric compression were analyzed. The longitudinal reinforcement of the column consisted of two rebars $\phi 12 \mathrm{~mm}$, steel grade A-IIIN, $f_{y k}=608$ $\mathrm{MPa}, E_{s}=224 \mathrm{GPa}$ and the transverse reinforcement consisted of stirrups $\phi 6 \mathrm{~mm}$, steel grade A-I. The columns were made of concrete $f_{c m}=31.9 \mathrm{MPa}$. $E_{c m}=31 \mathrm{GPa}$. The failure loads and the corresponding eccentricities were determined in these tests as: $P_{1}=1548 \mathrm{kN}, e_{1}=0 \mathrm{~mm} ; P_{2}=1386 \mathrm{kN}, e_{2}=16$ $\mathrm{mm} ; P_{3}=1098 \mathrm{kN}, e_{3}=32 \mathrm{~mm}$. The ultimate strain in concrete at failure was assumed in calculations as $-2.1 \%$. The characteristic failure mechanisms of the tested specimens occurred in the form of crushing the concrete in the upper part of the structure members and yielding the longitudinal reinforcing steel. A good conformity between the calculated and experimental results are confirmed by the values collected in Table 10 In author's opinion, further experimental work is needed concerning the post-critical behaviour of RC columns under eccentric compression.

\section{Conclusions And COMments}

Our numerical results have confirmed that the elaborated analytical deformation model (taking into account the effect of concrete softening) may be used to determine the strains in rectangular cross-sections of $\mathrm{RC}$ compressed structure members. It can be applied to predict the behaviour of such structure members.

The current Matlab's implementations of the global optimization algorithms (ga and particle swarm) do not seem to be suitable for our application. In genetic algorithm (ga), elitism is used (part of the previous population survives to the next one). But it does not ensure finding the correct solution. The particle swarm procedure also does not guarantee the computation of the correct solution. Of course, we may tune some of their parameters, but we do not expect to gain much from that. Our experiments with the local search method have frequently shown the existence of several global minima. All of them are almost equally good from the point of view of a numerical calculations specialist. We decided to select them by means of the Hamilton minimum energy principle. In our opinion, from the existing global optimization methods, the most promising may be the clusterization methods (see for instance Törn and Żilinskas [35]). The calculated results conform to the experimental ones. The proposed approach enables to evaluate the structural safety of tower-like structures with rectangular sections without testing the drilling-out cores taken from the structure. It may also be useful in the structural design and maintenance.

\section{REFERENCES}

[1] M. Lechman, P. Lewiński. Generalized section model for analysis of reinforced concrete chimney weakened by openings. Eng Trans 49(1):3-28, 2001. 
[2] M. Knauff. Calculations of reinforced concrete structures according to EC 2. Scientific publisher PWN, Warsaw, Poland, 2013.

[3] M. Knauff, A. Golubiska, P. Knyziak. Tables and formulae for the design of reinforced concrete structures with calculation examples. Scientific publisher PWN, Warsaw, Poland, 2013.

[4] H. Nieser, V. Engel. Structure of industrial chimneys. Commentary on DIN 1056. German Institute for Standardization, Berlin, Germany, 1986.

[5] CICIND. Model Code for Chimneys, Part A: The Shell. Sec. Ed., Rev. 1. CICIND, Zurich, Switzerland, 2001.

[6] M. Lechman, A. Stachurski. Nonlinear section model for analysis of RC circular tower structures weakened by openings. Struct Eng and Mech 20(2):161-172, 2005. DOI:/10.12989/sem.2005.20.2.161

[7] M. Lechman. Load-carrying capacity and dimensioning of ring cross-sections under eccentric compression. Scientific Papers of the Building Research Institute, Dissertations, Warsaw, Poland, 2006.

[8] M. Lechman. Resistance of RC annular cross-sections with openings subjected to axial force and bending. Eng Trans 56(1):43-64, 2008.

[9] M. Lechman. Dimensioning of sections of concrete members under compression according to Eurocode 2. Examples of use. Building Research Institute Publications, Warsaw, Poland, 2011.

[10] M. Lechman. Resistance of reinforced concrete columns subjected to axial force and bending. Transportation Res Procedia 14C:2411-2420, 2016. DOI:10.1016/j.trpro.2016.05.283

[11] T. Majewski, J. Bobiński, J. Tejchman. FE analysis of failure behaviour of reinforced concrete columns under eccentric compression. Eng Struct 30(2):300-317, 2008. DOI:10.1016/j.engstruct.2007.03.024.

[12] E. Rodrigues, O. Manzoli, L. Bitencourt Jr., et al. Failure behavior modeling of slender reinforced concrete columns subjected to eccentric load. Latin Amer $J$ of Solids and Struct 12(3):520-541, 2015. DOI:10.1590/1679-78251224

[13] J. Kim, S.-S. Lee. The behavior of reinforced concrete columns subjected to axial force and biaxial bending. Eng Struct 22(11):1518-1528, 2000. DOI:10.1016/S0141-0296(99)00090-5

[14] G. Campione, G. . Minafo. Applicability of over-coring technique to loaded RC columns. Struct Eng and Mech 51(1):181-197, 2014. DOI:10.12989/sem.2014.51.1.181

[15] G. Campione, M. Fossetti, M. Papia. Behavior of fiber-reinforced concrete columns under axially and eccentrically compressive loads. ACI Struct J 107(3):272-281, 2010.

[16] N. Lloyd, B. Rangan. Studies on high-strength concrete columns under eccentric compression. ACI Struct J 93(6):631-638, 1996.

[17] J. Bonet, M. Romero, P. Miguel. Effective flexural stiffness of slender reinforced concrete columns under axial forces and biaxial bending. Eng Struct 33(3):881893, 2011. DOI:10.1016/j.engstruct.2010.12.009
[18] M. Ye, Y. Pi, M. Ren. Experimental and analytical investigation on RC columns with distributed-steel bar. Struct Eng and Mech 47(6):741-756, 2013. DOI:10.12989/sem.2013.47.6.741.

[19] C. Xu, L. Jin, Z. Ding, et al. Size effect tests of highstrength RC columns under eccentric loading. Eng Struct 126:78-91, 2016. DOI:10.1016/j.engstruct.2016.07.046

[20] T. Trapko, M. Musiał. The effectiveness of CFRP materials strengthening of eccentrically compressed reinforced concrete columns. Arch of Civil and Mech Eng 11(1):249-262, 2011. DOI:10.1016/S1644-9665(12)60187-3

[21] T. Trapko. Effect of eccentric compression loading on the strains of FRCM confined concrete columns. Constr and Building Mat 61:97-105, 2014. DOI:10.1016/j.conbuildmat.2014.03.007

[22] M. Hadi, T. Le. Behaviour of hollow core square reinforced concrete columns wrapped with CFRP with different fibre orientation. Constr and Building Mat 50:62-73, 2014. DOI:10.1016/j.conbuildmat.2013.08.080

[23] T. El Maaddawy, M. El Sayed, B. Abdel-Magid. The effects of cross-sectional shape and loading condition on performance of reinforced concrete members confined with carbon fiber-reinforced polymers. Mat and Design 31(5):2330-2341, 2010. DOI:10.1016/j.matdes.2009.12.004

[24] B. Csuka, L. Kollar. Analysis of FRP columns under eccentric loading. Comp Struct 94(3):1106-1116, 2012. DOI:10.1016/j.compstruct.2011.10.012

[25] S. Elwan, A. Rashed. Experimental behavior of eccentrically loaded rc short columns strengthened using GFRP wrapping. Struct Eng and Mech 39(2):207-221, 2011. DOI:/10.12989/sem.2011.39.2.207.

[26] P. Sadeghian, A. Rahai, M. Ehsani. Experimental study of rectangular RC columns strengthened with CFRP composites under eccentric loading. J for Comp for Constr 14(4):443-450, 2010. DOI:10.1061/(ASCE)CC.1943-5614.0000100

[27] R. Eid, P. Paultre. Compressive behaviour of FRP-confined reinforced concrete columns. Eng Struct 132:518-530, 2017. DOI:10.1016/j.engstruct.2016.11.052

[28] Y. Wu, C. Jiang. Effect of load eccentricity on the stress-strain relationship of FRP-confined concrete columns. Comp Struct 98:228-241, 2013. DOI:10.1016/j.compstruct.2012.11.023

[29] M. Quiertant, J. Clement. Behavior of RC columns strengthened with different CFRP systems under eccentric loading. Constr and Building Mat 25(2):452460, 2011. DOI:10.1016/j.conbuildmat.2010.07.034.

[30] J. Lee, Y. Kim, S. Kim, J. Park. Structural performance of rectangular section confined by squared spirals with no longitudinal bars influencing the confinemen. Arch of Civil and Mech Eng 16(4):795-804, 2016. DOI:10.1016/j.acme.2016.05.005

[31] V. Kumar, P. V. Patel. Strengthening of axially loaded columns using stainless steel wire mesh (SSWM) numerical investigations. Struct Eng and Mech 60(6):979 999, 2016. DOI:10.1016/j.conbuildmat.2016.06.109 
[32] M. Lechman, A. Stachurski. Determination of stresses in RC eccentrically compressed members using optimization methods. In Computer Methods in Mechanics (CMM2017): Proceedings of the 22nd International Conference on Computer Methods in Mechanics, AIP Conference Proceedings, vol. 1922, pp. 1-11. AIP Publishing, ASCE, Reston, VA, 2018. DOI:10.1063/1.5019133

[33] Eurocodes. 1992-1-1 Eurocode 2: Design of concrete structures Part 1-1: general rules and rules for buildings. Joint Research Center, EUROCODES, European Commission, 2010.
[34] A. Stachurski. Introduction to Optimization, (in polish: Wprowadzenie do optymalizacji). Publishing House of the Warsaw University of Technology, Warsaw, Poland, 2009.

[35] A. Törn, A. Żilinskas. Global Optimization. Springer Verlag, Berlin, Heidelberg, Germany, 1989. 